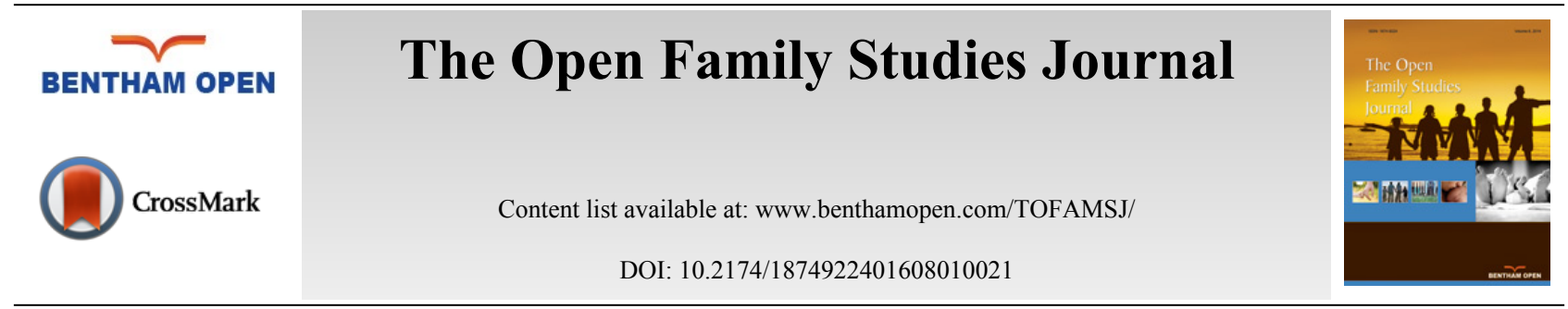

RESEARCH ARTICLE

\title{
A Narrative Account of the Life Experiences of Older Somali Refugee Women
}

\author{
Mehra Shirazi $^{1, *}$ and Kaltun Caynan ${ }^{2}$ \\ ${ }^{I}$ Department of Women, Gender, and Sexuality Studies, Oregon State University, Corvallis, OR 97331, USA \\ ${ }^{2}$ Oregon Somali Family Education Center, 2032 SW Merlo Station Apartments, Beaverton, OR 97006, USA
}

Received: September 27, 2016

Revised: December 05, 2016

Accepted: December 05, 2016

\begin{abstract}
The purpose of this paper was to explore the factors that shape identity, agency, and quality of life for older Somali refugee women. The author used a narrative inquiry approach to analyze the life stories of 12 Somali refugee women. Narratives were analyzed for both content and form, and three main themes were identified: (1) journey of trauma and coping, (2) identity and perceptions of home and belonging, and (3) navigating a complex health care system. The findings underscore the importance of understanding the complexity of Somali refugee women's voices in response to coping with trauma, resettlement, and belonging.
\end{abstract}

Keywords: Somali Women, Narrative, Trauma, Identity, Health.

\section{INTRODUCTION}

Over thirty-years of conflict in Somalia has led to a massive population displacement. With the adoption of the Refugee Act of 1980, the United States instigated a refugee policy, established a federal office, and provided federal financial assistance for the resettlement of refugees. The U.S. Department of State reports that since 1975, they have resettled over 3 million refugees in the United States. By July 2012, the number of Somali refugees worldwide has exceeded one million. Somali refugees began arriving in the United States since 1991. The United States has resettled close to 100,000 Somali refugees to date [1].

Somali refugees face many challenges during the resettlement process in new countries. Since the start of the civil war in 1991, research indicates that Somali refugees have endured mass displacement, family loss, political and ethnic discrimination, as well as violence, such as rape and torture [2,3]. Additional research shows that forced migration is a life altering process and Somali refugees have difficulties related to social exclusion, unemployment, and discrimination. They often struggle with poverty, poor housing, racism, and barriers to accessing education and health services [4].

Very little has been written about older Somali women's experiences of forced migration and resettlement. Using a narrative inquiry approach in this paper, I explore the factors that shape identity, agency, and quality of life in old age for Somali refugee women. A better understanding of their experiences is an essential tool for the development of culturally specific and effective interventions designed to address their needs.

\section{RESEARCHER POSITIONALITY}

As an immigrant woman researcher who has primarily worked with female immigrant and refugee communities on socio-cultural barriers to accessing health care, the researcher is familiar with providing the continuation of a deeper understanding for Somali refugee women. Previous research of working with Afghan refugees, have emphasized how critical it is to engage the community in an authentic way in order for the women to tell their stories as an empowering

* Address correspondence to this author at the Department of Women, Gender, and Sexuality Studies, Oregon State University, Corvallis, OR 97331, USA; Tel: 541-737-9274; E-mail: mehra.shirazi@oregonstate.edu 
tool for identifying their unique complexities [5]. This research is a preliminary assessment of the women's stories, particularly the older population who have been significantly underrepresented within the research community.

\section{THEORETICAL FRAMEWORK}

This paper draws upon trauma theory and feminist theory and empowerment perspectives [6, 7]. It highlights the cumulative nature of traumatic and adverse events and identifies and centers marginalized voices to explore the impact of systematic oppression in addressing and healing from trauma $[8,9]$.

"Trauma" may be described as an event that causes intense feelings of horror, fear, vulnerability, and anxiety, such as physical or sexual assault, torture, armed conflict and war, and intimate partner violence [9]. Feminist theories have historically been concerned with the disempowering effects of trauma on women and marginalized groups, and have consistently made an effort to recognize these experiences as products of oppressive systems $[8,9]$.

Additionally, feminist theories recognize that trauma experienced by women, particularly sexual torture, is used as a weapon to destroy family, community, and culture [10]. Emphasizing the personal and political dimensions of oppression, feminist theory provides the necessary framework to better understand the invisibility perceived and experienced by women refugees. Feminist theory also calls for responses to trauma that address systemic roots of violence and construct interpersonal empowerment that highlight self-determination and socio-structural healing relationships [11]. Applying a feminist lens to recognize the impact of traumatic violence and forced migration on the extended family, culture, language, rituals, and social exchanges is an essential part of developing an informed narrative for working within these communities.

Hein [12] argues that the social, cultural, and historical background of an immigrant population shapes the ways in which it adapts to resettlement but because of social taboos against adopting culture to explain difficulties, we in the United States instead tend to avoid placing emphasis on immigrants' culture or pre-migration experience. By definition, refugees resettled in the US have experienced human rights violations, and most have left family, friends, and social networks behind, meaning that depression, PTSD, anxiety and others mental health concerns are disproportionally prevalent in these communities [13]. Jaranson et al. [14] highlighted the need to recognize the prevalence of torture among African refugees, particularly women who were tortured at the same rates as men, and develop appropriate resources. Women who reported higher levels of trauma were older, had more family responsibilities, less education, and were less likely to speak English [15]. Shannon, O’Dougherty, and Mehta [16] found that in a sampling of refugees in the Midwest two-thirds had never discussed their history of trauma with their physicians, and that their physicians had never asked. Additionally, these participants were unaware of the ways in which trauma affects health and, in deference to physicians' authority, were unlikely to initiate conversations or make requests.

Narrative analysis is particularly suited to the assessment of need. Integrating intersectional feminist theory, aging, and life experience, it places the 'subject' as the driver of the inquiry allowing for the increased complexity; indeed Randall [17] discusses ageing as individuals increasing rather than decreasing in complexity. Narrative is particularly valuable in feminist scholarship as it allows for "...sequence and consequence: Events are selected, organized, connected, and evaluated as meaningful for a particular audience" [18]. Thus, participants are able to relate their life experience organically allowing, "respondents in various settings, such as interviews, to impose order on the flow of experience to make sense of events and actions in their lives" [19].

\section{METHODS}

This paper draws particularly the findings from storytelling circles and life-story interviews with 12 Somali women refugees between the ages $60-76$, who are living in the same small metropolitan area of the western United States. None of the participants presented with obvious cognitive difficulties. Qualified participants were recruited through snowball sampling by bilingual community leaders and invited in groups of 6 on two different occasions through the local community center. These groups were part of a larger series of focus groups within the community and participants signed consent forms before beginning. Interviewers opened the sessions with a brief discussion of the project and encouraged participants to tell their story. Using these circles, Somali women's narratives about their life experiences were collected. Using a process grounded in oral history, storytelling was encouraged to appeal to the oral traditions of Somali culture. The objective was to let Somali women speak for themselves, speak back, or speak out. Embedded within narrative approaches, the focus was on counteracting marginalization where the conversations position the respondent as a narrator of their life history while engaging participants' agency to express their life experience [20]. Narrative approaches mobilize participants' voices and provide a space to give words to their life 
histories within a broader social context [21]. An interpreter from the local Somali community was available to immediately aid with the interpretation of stories of the participants unable to speak English or to interpret conversations when needed and the stories were transcribed verbatim.

A thematic analysis of the data was conducted [22], coding by significant sentences and paragraphs relating to themes and narratives. A life history was constructed for each of the participants by creating a summary of their narratives that were told in their own words [23]. Next, the narratives were grouped according to common core concepts and coded. Due to the limited number of individuals able to participate the intent was not to reach saturation but to begin a preliminary exploration of themes and concerns of these women.

\section{FINDINGS}

The average age of the participants was 63 and all of them had lived in the US for 6 years or longer. The participants' narratives were reflected in three main themes: 1) journey of trauma and coping, 2) identity and perceptions of home and belonging, and 3) navigating a complex health care system

\section{Journey of Trauma and Coping}

The women recognized that current reality and daily lives were shaped by past experiences of trauma. Many repeatedly referred to the events from the Somali civil war that affected the current welfare of their families and their kin. Many had witnessed their homes being attacked and their family members being robbed, tortured, raped and killed. The majority had also experienced trauma during transition in other countries as well as upon arrival and resettlement in the United States. They shared the experience of arriving with no belongings or resources and with significant health problems from the trauma and misery of the civil war.

"In the war, I lost close family members and after all this time many are still missing. I was separated from my daughter and she is still missing. I mourn her every day."

In addition to recounting their experiences of trauma, the women explained how exposure to past trauma made it more difficult to cope with life's challenges in the United States.

"All the bad things that happened are still in my memory. I will never forget, never. I try but I can never be fully happy, there is always this heaviness in my heart."

Despite their experiences, none of the participants conveyed a sense of victimhood. Their present interpretation of themselves was as survivors and agents of hope for their families. They explained the importance of religion, social support, and community resources as coping mechanisms that helped them and their families adjust to the resettlement process and cope with many forms of trauma.

"Our Somali community is very resilient and strong ; we help each other...those with more experience help the new ones. At the mosque, we pray together and the women talk about their problems, and sometimes cry together."

\section{Identity and Perceptions of Home and Belonging}

The women felt very proud of their Somali identity and said they tried hard to raise their children as "Somalis". One of the women stated, "No matter where your children are born we all want our children to have the Somali culture. We don't want to lose that." The women described their experience of loneliness and isolation from being in a new country and the impact of this experience on their health, "Back in Somalia we have the extended family, and there is no such thing as being alone."

The participants spoke of belonging in terms of their old homes as well as their new homes; how the civil war had made it very difficult to belong to their old home. They spoke fondly of their ways of living and strong kinship and how suddenly they lost everything.

They described old age in Somalia as a time to be free from worries and to be supported by one's family and children. They recounted a sense of loss associated with not only the loss of material wealth but of their social standing and status. The participants discussed how forced migration had also resulted in the loss of autonomy and referred to the different family structures in the US, which they saw as diminishing their respectability and position within the family.

"In Somalia, old age is something to be proud of. There, old people enjoy respect, but here it is different. I feel alone and helpless. My children are too busy for me. Sometimes I sit home all day with none to speak to. I feel sad and my health is getting worse." 
Social isolation, including the stress of language difficulties, was also exacerbated by the breakup of families in the refugee and resettlement process. Men of the family are disproportionately gone, either killed or forced to remain in refugee camps as women and children were resettled in the United States.

"Many women lost their husbands in Somalia or in refugee camps. Many of us are living as single women. Also the husbands who came to the U.S. are now separated from the women. They (men) don't help with money, so the women left their husbands"

The participants noted the Somali language is integral to their identity and speaking Somali with parents, older relatives, and community elders is essential for the preservation of a strong family. They felt that the use of their native language at home which preserves the continuity of family structures is slowly disappearing. In addition, viewing of their resettlement as a not necessarily permanent leaving of Somalia heightens the concern for the diluting of language and culture.

"Our language is very important, it is what ties us to our culture...I feel sad that my grandchildren don't speak Somali, what if they decide to go back one day?"

\section{Navigating a Complex Health Care System}

Somali women's interactions with the health care system were often described as frustrating and disappointing. The women felt that mainstream providers had little understanding of the complexities of their life and the impact of war trauma on their health. Many of the women suffer from tangible, physical health problems, including diabetes, high blood pressure, and arthritis, but lacked holistic care that addressed their mental health and social isolation in addition to physical concerns. Additionally, they felt that language barriers particularly hampered the inability of health care providers in response to the needs of the Somali women. They related how their lack of proficiency in English posed problems for accessing services, and placed significant limitations on their mobility and in forming new social networks. Many of the Somali women mentioned they had been attending English language classes for years but found learning a new language extremely difficult. As one woman explained, “I don't speak English well...this language barrier is one of the most difficult things that we experience. I can't explain things completely, so it's not easy to make new friends." They stressed the need to improve interpretation and translation services, adding that it takes time to build a trusting relationship and be at ease with interpreters and physicians.

"It's uncomfortable to talk about all your health problems, especially private issues. It should be someone who you see frequently, someone who can explain things correctly."

While they did want familiar faces in the exam room there was also a concern expressed that, due to a lack of available interpreters, at times family members or people known from the community had to interpret, making frank discussions of personal or sensitive issues, particularly trauma, particularly fraught in a small community.

The participants also identified a lack of understanding of mental health conditions and cultural barriers as impediments to accessing mental health care. They mentioned, “... most of them (physicians) don't ask about their past experiences of war and trauma", and that how most Somalis "will not talk about these issues" unless they are asked directly.

There was a strong belief among the participants that they were perceived as the 'other'. Many discussed a sense of marginalization, and as a result, they were skeptical of the health care system and most service providers. These obstacles deepened their stress around accessing health care services. One of the participants shared, "Sometimes you experience racism, the manner of some of the staff, the way they look at you, the way they speak to you, as if you know nothing." These realizations point out that it's the social relations of power, not culture that stipulate the contexts and contents of discrimination. Such structural changes involve a call for a change in attitudes, practices, and conceptual frameworks. And as Jiwani implies, this requires health care professionals' awareness of the larger impact of structural violence, systematic racism, and endorsement of social justice [24].

\section{CONCLUSION}

Stories give women a space to talk, and to present their life experiences from their own perspectives. Chandra Mohanty has discussed the importance of "testimonials, life stories, and oral narratives, as a significant mode of remembering and recording experiences and struggles" [25] and of carrying these experiences into the realm of accepted knowledge of everyday life. Such epistemologies of healing are grounded in centering marginalized voices 
and the recognition of their historical positioning to construct knowledge for practice and praxis. To do so, Anderson [26] asserts that a postcolonial feminist perspective provides the tools for analyzing how the intersecting systems of oppression shape the experiences and meanings of life and well-being for women of color in the diaspora. Such an approach challenges us to examine the unequal relations of power and the ways in which dominant groups have redefined local meanings, and dictated social structures. Additionally, it highlights the need to shift from a thinking that places culture as simply a social characteristic and recognizes it as a "...fluid and dynamic process, which is important to the everyday situation of immigrant women" [27].

As Hua points out in, "Diaspora, Memory, and Identity", documenting collective memories of homeland as well as life experiences enable marginalized women not only to resist the "colonial tropes of victimization of and Otherness," but also to "act as a catalyst for self-recovery and community-building" [28]. The most important theme connecting the stories shared by the participants is the ways they contradict their stereotypical depiction in the dominant culture as passive victims. Such counter-narratives open up spaces for critical examination of the nature of various identities, such as gender, ethnicity, education, race, class, religion, and sexuality, as well as their intersections with marginalization and their impact on quality of life and pathways to healing. While many of the issues are issues service providers and clinicians face with any immigrant population these initial findings suggest several straightforward clinical interventions. It is important for local clinicians who treat a sizeable Somali population to understand the history of Somalia's ongoing conflict. Therefore, developing a culturally sensitive exam screening for trauma may address the feelings of reticence by physicians to ask about something so personal. Additionally, while increased culturally competent mental health services may be indicated, there may also be smaller community-based interventions that can decrease social isolation and increase their feelings of status and respect as community elders. Further research is indicated to build on these initial finding and develop culturally competent programming to address health and wellbeing in Somali communities throughout the United States.

\section{CONFLICT OF INTEREST}

The authors confirm that this article content has no conflict of interest.

\section{ACKNOWLEDGEMENTS}

Declared none.

\section{REFERENCES}

[1] United Nations High Commissioner for Refugees Refugees in the horn of Africa: Somali displacement crisis: Information sharing portal 2015. Available from: http://data.unhcr.org/horn-of-africa/regional.php

[2] Kinzie JD, Sack W, Angell R, Clarke G, Ben R. A three-year follow-up of Cambodian young people traumatized as children. J Am Acad Child Adolesc Psychiatry 1989; 28(4): 501-4.

[http://dx.doi.org/10.1097/00004583-198907000-00006] [PMID: 2768143]

[3] Locke CJ, Southwick K, McCloskey LA, Fernández-Esquer ME. The psychological and medical sequelae of war in Central American refugee mothers and children. Arch Pediatr Adolesc Med 1996; 150(8): 822-8.

[http://dx.doi.org/10.1001/archpedi.1996.02170330048008] [PMID: 8704888]

[4] Danso R. From "There" to "Here": An investigation of the initial settlement experiences of Ethiopian and Somali refugees in Toronto. Geo J 2002; 56: 3-14. [http://dx.doi.org/10.1023/A:1021748701134]

[5] Shirazi M, Bloom J, Shirazi A, Popal R. Afghan immigrant womens knowledge and behaviors around breast cancer screening. Psychooncology 2013; 22(8): 1705-17.

[http://dx.doi.org/10.1002/pon.3216] [PMID: 23225210]

[6] Kubiak SP. Trauma and cumulative adversity in women of a disadvantaged social location. Am J Orthopsychiatry 2005; 75(4): 451-65. [http://dx.doi.org/10.1037/0002-9432.75.4.451] [PMID: 16262505]

[7] Turner RJ, Lloyd DA. Lifetime traumas and mental health: the significance of cumulative adversity. J Health Soc Behav 1995 ; 36(4): 360-76. [http://dx.doi.org/10.2307/2137325] [PMID: 8719054]

[8] Dietz CA. Responding to oppression and abuse: A feminist challenge to clinical social work. Affilia 2000; 15: 369-89. [http://dx.doi.org/10.1177/08861090022094001]

[9] Kulkarni SJ, Kennedy AC, Lewis CM. Using a risk and resilience framework and feminist theory to guide social work interventions with adolescent mothers. Fam Soc 2010; 91: 217-24.

[http://dx.doi.org/10.1606/1044-3894.3998]

[10] Buss D. Rethinking 'rape as a weapon of war'. Fem Leg Stud 2009; 17(2): 145-63. 
[http://dx.doi.org/10.1007/s10691-009-9118-5]

[11] Harvey MR. Towards an ecological understanding of resilience in trauma survivors. J Aggress Maltreat Trauma 2007; 14: 1-3. [http://dx.doi.org/10.1300/J146v14n01_01]

[12] Hein J. Ethnic origins: The adaptation of Cambodian and Hmong refugees in four American cities. New York, NY: Russell Sage Foundation 2006.

[13] Jackson K. Treating trauma in america's refugees. Soc Work Today 2016; 16(4): 10.

[14] Jaranson JM, Butcher J, Halcon L, et al. Somali and Oromo refugees: correlates of torture and trauma history. Am J Public Health 2004; 94(4): 591-8.

[http://dx.doi.org/10.2105/AJPH.94.4.591] [PMID: 15054011]

[15] Robertson CL, Halcon L, Savik K, et al. Somali and Oromo refugee women: trauma and associated factors. J Adv Nurs 2006; 56(6): 577-87. [http://dx.doi.org/10.1111/j.1365-2648.2006.04057.x] [PMID: 17118037]

[16] Shannon P, ODougherty M, Mehta E. Refugees perspectives on barriers to communication about trauma histories in primary care. Ment Health Fam Med 2012; 9(1): 47-55. [PMID: 23277798]

[17] Randall W. Narrative and chaos: Acknowledging the novelty of lives in time. Interchange 2007; 38(4): 1-24. [http://dx.doi.org/10.1007/s10780-007-9037-9]

[18] Riessman C, Speedy J. Narrative inquiry in the psychotherapy professions. In: Clandinin D, Ed. Handbook of narrative inquiry. London: Sage 2007.

[http://dx.doi.org/10.4135/9781452226552.n17]

[19] Phoenix C, Smith B, Sparkes A. Narrative analysis in aging studies: A typography for consideration. J Aging Stud 2010; 24: 1-11. [http://dx.doi.org/10.1016/j.jaging.2008.06.003]

[20] Chase SE. Narrative inquiry: Multiple lenses, approaches, voices. In: Denzin NK, Lincoln YS, Eds. The Sage Handbook of Qualitative Research. London: Sage 2005; pp. 651-79.

[21] Holstein JA, Gubrium JF. The self we live by: Narrative identity in a postmodern world. New York: Oxford University Press 2000.

[22] Ezzy D. Qualitative Analysis: Practice and Innovation. Sydney: Allen \& Unwin 2002.

[23] Flick U, von Kardorff E, Steinke I, Eds. A companion to qualitative research. Thousand Oaks: Sage 2004.

[24] Jiwani Y. Discourses of Denial: Mediations of Race, Gender, and Violence. Vancouver: UBC Press 2006.

[25] Mohanty CT. Feminism without borders: decolonizing theory, practicing solidarity. London: Duke University Press 2003. [http://dx.doi.org/10.1215/9780822384649]

[26] Anderson JM, McCann EK. Toward a post-colonial feminist methodology in nursing research: exploring the convergence of post-colonial and black feminist scholarship. Nurse Res 2002; 9(3): 7-27. [http://dx.doi.org/10.7748/nr2002.04.9.3.7.c6186] [PMID: 11985150]

[27] Maureen OMahony J, Truong Donnelly T. A postcolonial feminist perspective inquiry into immigrant womens mental health care experiences. Issues Ment Health Nurs 2010; 31(7): 440-9. [http://dx.doi.org/10.3109/01612840903521971] [PMID: 20521913]

[28] Vijay A, Ed. Diaspora, Memory, and Identity: A Search for Home. Toronto: University of Toronto Press 2005.

(C) Shirazi \& Caynan; Licensee Bentham Open

This is an open access article licensed under the terms of the Creative Commons Attribution-Non-Commercial 4.0 International Public License (CC BY-NC 4.0) (https://creativecommons.org/licenses/by-nc/4.0/legalcode), which permits unrestricted, non-commercial use, distribution and reproduction in any medium, provided the work is properly cited. 